\title{
Social Factors and Health: Description of a new Norwegian twin study
}

\author{
Julia Kutschke ${ }^{1}$, Anina Falch ${ }^{1}$, Ingunn Brandt ${ }^{1}$, Thomas S. Nilsen ${ }^{1}$, Astanand Jugessur ${ }^{1}$, \\ Ulrich Halekoh $^{2}$, Teresa E. Seeman ${ }^{3}$ and Jennifer R. Harris ${ }^{1}$ \\ 1) Norwegian Institute of Public Health, Norway \\ 2) University of Southern Denmark, Denmark \\ 3) University of California, Los Angeles, USA \\ Correspondence: Jennifer.Harris@fhi.no
}

\begin{abstract}
A compelling literature substantiates that our social worlds have significant and far-reaching effects on health and well-being throughout life. Yet, few studies of social factors and their effects on health have been embedded within the twin design. Towards this end, we have initiated a new twin study on social factors and health which will investigate the genetic and environmental influences on social environments, and explore how social environments mediate these influences on physical and mental health. Herein, we describe the study sample, response rates and measures. Twins born 1935-1960 and 1967-1974 were invited to complete a questionnaire and these data were supplemented with information on cardiovascular disease and cancer through linkage to national health registries. Among the 10655 twins who were contacted, responses were received from 5446 individuals (1989 pairs and 1468 single responders). The subsample of pairs where both twins responded includes 1004 identical (MZ) pairs and 985 fraternal (DZ) pairs. The overall individual and pairwise response rates were $51 \%$ and $37 \%$, respectively. The average age is 61.54 years, $56.1 \%$ of the responders are female and $46.1 \%$ are identical twins. MZ twins were more likely to participate than DZ twins. Sex and age effects were statistically significant for many of the psychosocial measures and for measures of support and strain in the social network. There were no differences in the social networks between twins in pairs where both twins responded and twins in pairs where only one twin responded.
\end{abstract}

This is an open access article distributed under the Creative Commons Attribution Licence, which permits unrestricted use, distribution, and reproduction in any medium, provided the original work is properly cited.

\section{INTRODUCTION}

We describe a new Norwegian twin study that will explore diverse social environments and how they modify health. Our focus on social environments stems from a large epidemiological literature documenting that social worlds have significant and far-reaching effects on physical and psychological health throughout life (17). Social integration and engagement are associated with improved growth and development in children, lower biological risk profiles in adults $(8,9)$, reduced risks for cognitive and physical decline (10-13), greater resilience to a host of somatic diseases (14), lower risks for disease (15) and disability (16), and greater longevity $(17,18)$. These effects are sizeable and confer as great a risk to health and mortality as do the most important known risk factors such as smoking, obesity, high blood pressure and sedentary lifestyle (3).

While the initial research on social engagement focused primarily on beneficial effects of social support, later studies have begun to illuminate the equally important negative effects of social conflict (19-21). Likewise, perceptions of social isolation are also predictive of physical and mental health, with greater frequency of perceived social conflict associated with poorer biological risk profiles (20-22) and mortality $(23,24)$. Experimental data complement these findings and demonstrate that being in socially supportive relationships buffers against illness and improves resili- ence to physical and emotional stress $(25,26)$. Perceived stress has also been linked to higher risks for a range of major health outcomes, including cardiovascular disease, clinical depression, autoimmune disease, HIV/AIDS and respiratory infections (27-29).

Research into causal effects behind these associations is also beginning to accrue. Findings suggest that deficits in social worlds impact health through physiologic dysregulation. This occurs in conjunction with chronic activation of immune, metabolic and neuroendocrine systems that influence disease-related pathways (23,30,31). Results from large longitudinal studies that analyzed how social relationships impact health and longevity are also providing novel insights into the life-course process through which these paths unfold (32).

Despite this large literature, few studies have utilized the twin design to explore social environments and their effects on health. However, new insights into the nature of these relationships can be gained by leveraging unique features of the twin design. First, twin studies can control for potential confounding that can arise when there is overlap between the genetic and environmental factors that influence both the social environments (exposures) and the health outcomes. Second, twin studies can help elucidate the genetic and environmental covariance structure underlying the relationships between different social environmental measures (33) and between social environments and 
health. Finally, twin models are valuable for testing gene-environmental interactions whereby social environments moderate genetic influences on health.

We describe a new twin study that will exploit the twin methodology to study social environments and their effects on health. The purpose of this paper is to present basic information about the study. This includes: 1) descriptions of the sample, measures and questionnaire response rates, 2) an overview of the psychosocial and social environmental measures, including tests for effects related to age, sex and the number of twins within a pair who responded, and 3) an assessment of the concordance for cardiovascular and cancer outcomes.

\section{DESCRIPTION OF DATA COLLECTED}

In 2014, we initiated a 12-page mail-out questionnaire study that collected extensive information about social environments and health from a large cohort of twins aged 40-80 years who are participants in the Norwegian Twin Registry (NTR) $(34,35)$. The twins were invited in two waves depending on the status of their consent to be in the NTR (first invitation sent in September 2014 to 4700 pairs, and second invitation sent in November 2014 to 654 pairs). One reminder was sent in the period from November-December 2014 to the twins who did not respond to their original invitation. Through linkage of the questionnaire data to national health registries, we have nearly complete ascertainment of cardiovascular diseases registered after 2012 and cancer from 1953 through 2012 among the participants, all coded using the ICD-10. The questionnaire included items about body composition, physical and mental health, medication use, health behaviors and lifestyle measures, social environments (perceived stress, social networks, loneliness and social support and social strain, relationship with co-twin), psychological well-being, self-perceived health, demographic information (education, retirement status, and income) and the degree to which physical and mental health interfered with daily functioning.

The measures of social environments and psychological status were based on established scales. The Perceived Stress Scale (PSS) developed by Cohen is the most widely used psychological scale for measuring perception of stress (36). The Social Network Index (SNI), also developed by Cohen and colleagues, provides information on the range of different types of social relationships maintained by the participant (37). Loneliness was measured using the R-UCLA loneliness scale (38). Measures of social support and strain related to major classes of social ties (spouse, family, friends) are from the national Mid-life in the US (MIDUS) study (http://www.midus.wisc.edu/) $(39,40)$. These scales have excellent psychometrics (41) and have been administered successfully via self-administered questionnaire to US adults from a wide range of educational backgrounds. A unique feature of our study is that we extended the measures of social support and strain to include the relationship with the co-twin. The questionnaire also included the Center for Epidemiologic Studies Depression Scale (CES-D) and the Mental Health Continuum Short Form (MHC-SF). The CES-D is a 20-item scale commonly used to measure depressive symptomatology (feelings and behaviors) in the general population. It demonstrates high internal consistency and adequate test-retest reliability (42). The MHC-SF scale consists of the 14 items selected from the longer MHC (40 item) scale that are the most prototypical items to measure emotional, psychological and social well-being. Estimates of internal consistency reliability in the MHC-SF are very high and the test-retest validity is considered adequate (43). To parallel the scale construction used in MIDUS we calculated two versions of the support and strain scales that reflect an average scale score and a total (summed) scale score. Positive scales are coded such that a higher value means better well-being, and negative scales are coded such that a higher value denotes worse well-being.

Information to determine a positive history of cardiovascular disease (CVD) or CVD symptomatology was obtained through linkage to the Norwegian Cardiovascular Disease Registry (NCDR), (http://www.fhi.no/artikler/?id=112056) and through several self-report items included in the questionnaire. The NCDR was formally established in 2012. It is a mandatory, person-identifiable national health registry containing information about patients with cardiovascular disease who were discharged from hospitals or out-patient clinics with ICD-10 codes relevant for CVD. It also includes information about deceased persons with CVD-related diagnoses as the underlying or contributing cause of death (44). Our information obtained through record linkage was updated through 2013. The questionnaire included six self-report CVD items including high blood pressure, arrhythmia, blocked artery/coronary disease/angina, cardiac infarction, other heart problems and stroke. An individual was assigned a positive score for CVD if he/she had at least one registration in the NCDR or responded yes to any of the CVD self-report items. A positive history of cancer was determined by registration in the national Cancer Registry of Norway (CRN). Since 1952, the $\mathrm{CRN}$ has systematically collected notifications on all cancer occurrences for the Norwegian population. The registration is considered to be close to complete from 1953 onwards; estimates based on a comprehensive study of quality indicate $98.8 \%$ completeness for the period from 2001 to 2005 (https://www.kreftregisteret. no/en/). At the time of record linkage to our study data, the CRN contained ICD-coded diagnoses from 1953 through November 2012.

The concordance estimates are based on the subsample of twins for which both twins participated and therefore precludes problems related to single or double ascertainment of pairs (45). The casewise concordance 


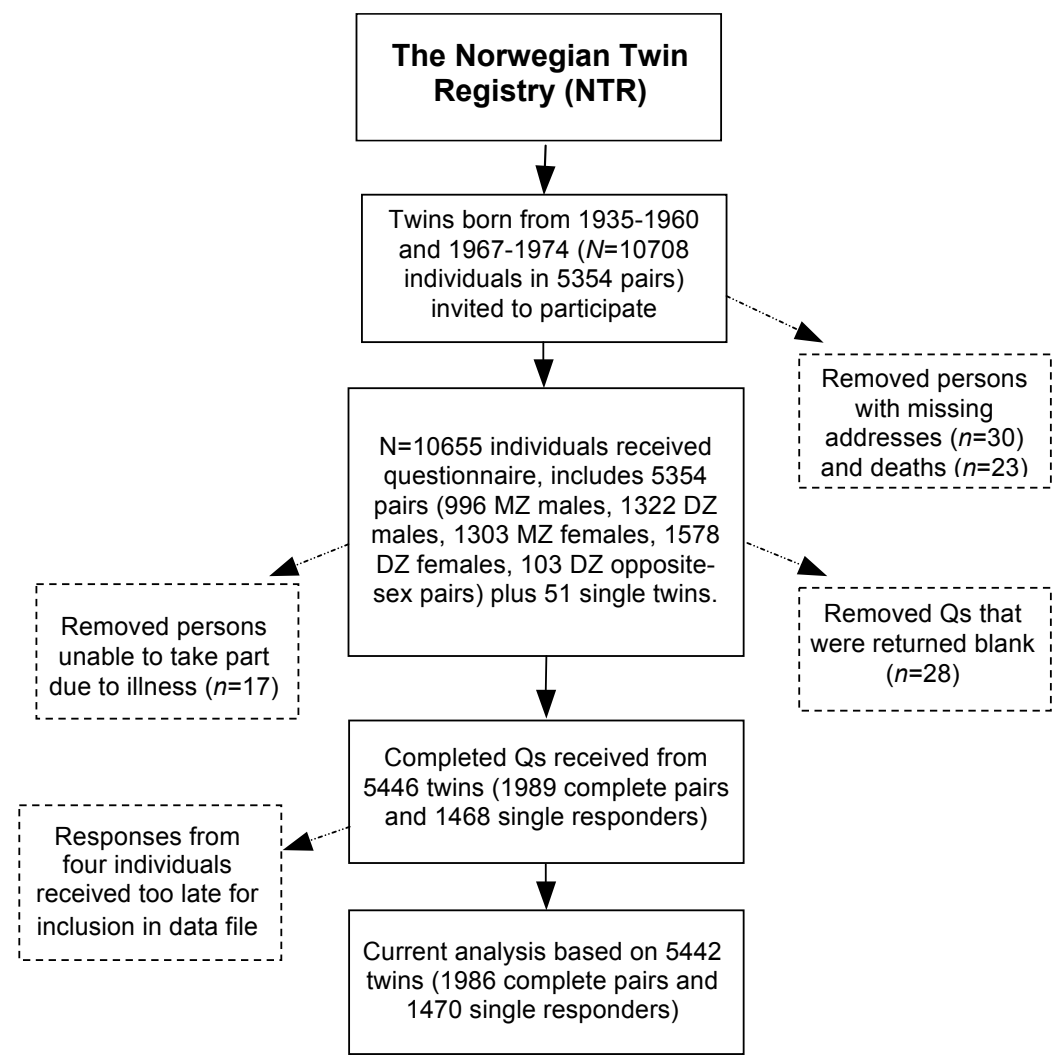

Figure 1. Flowchart showing recruitment to study.

Table 1. Overview of the number of pairwise and individual responses.

\begin{tabular}{lccccccc}
\hline Birth cohort & Pairs & $\begin{array}{c}\text { Pairs received } \\
\text { questionnaire }\end{array}$ & $\begin{array}{c}\text { Pairs only one } \\
\text { twin received } \\
\text { questionnaire }\end{array}$ & $\begin{array}{c}\text { Undeli- } \\
\text { verable } \\
\text { address }\end{array}$ & $\begin{array}{c}\text { Questionnaires } \\
\text { returned } \\
\text { unanswered }\end{array}$ & $\begin{array}{c}\text { Pairs } \\
\text { responded }\end{array}$ & $\begin{array}{c}\text { Single } \\
\text { responders }\end{array}$ \\
\hline $1935-1944$ & 1092 & 1078 & 14 & 2 & 14 & 392 & 279 \\
$1945-1954$ & 2270 & 2254 & 15 & 10 & 13 & 779 & 645 \\
$1955-1960$ & 1505 & 1484 & 21 & 17 & 1 & 484 & 433 \\
$1967-1974$ & 487 & 486 & 1 & 1 & 0 & 334 & 111 \\
\hline Total: & 5354 & 5302 & 51 & 30 & 28 & 1989 & 1468 \\
\hline
\end{tabular}

rate is the probability that one twin is affected with the disease, given that the other twin is affected.

The study was approved by the regional ethics committee.

\section{RESULTS}

\section{Response rates}

Figure 1 provides a flow-chart summarizing the recruitment of twins to this study. Briefly, twins born from 1935-1960 and from 1967-1974 were invited to participate in the study. Altogether, 5354 pairs were invited to participate. However, due to missing addresses (30 persons) and death (23 persons), 5302 of these pairs (996 MZ males (MZM), 1322 DZ males (DZM), 1303 MZ females (MZF), 1578 DZ females (DZF) and 103 DZ opposite-sex pairs (DZO)) plus 51 single twins received the questionnaire, altogether 10655 individuals. In response to the questionnaire invitation, 17 persons called (either themselves or represented by their spouse/ co-twin) and indicated that they were unable to participate due to illness. Twenty-eight of the returned questionnaires were totally blank. Altogether, completed questionnaires were received from 5446 twins, comprising 1989 complete pairs and 1468 single responders. Among the single responders, 1458 are from the 5302 pairs for which both twins received the questionnaire and 10 are from the 51 incomplete pairs for which only one twin received the questionnaire. Table 1 provides an overview of the number of questionnaires sent and received, stratified by 10 -year birth cohorts.

Table 2 presents the response rates by sex and zygosity. Logistic regression analyses using generalized estimating equations (clustering on twin pairs) were conducted to test for significant effects of sex or zygosity on the response rates. This approach takes dependency within the twin data into account. Findings revealed that $\mathrm{MZ}$ twins were more likely to answer the 


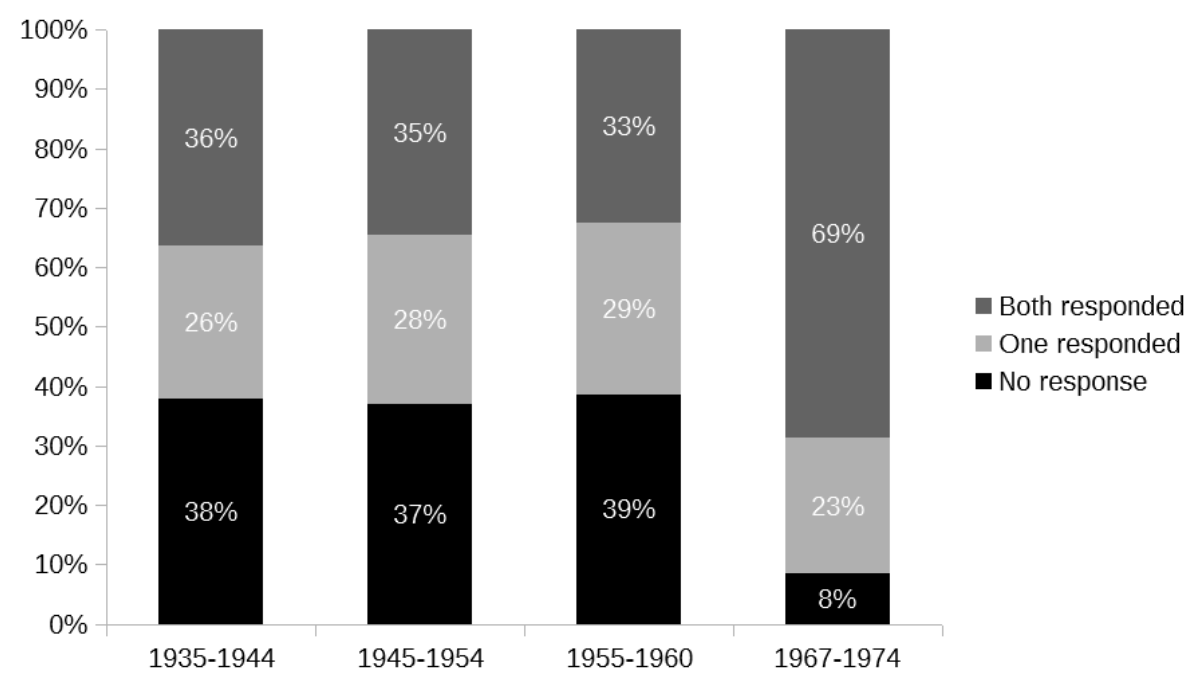

Figure 2. Response rates by birth-year groups based on the sample of 5302 pairs where both twins received the questionnaire.

Table 2. Pairwise and single response rates by zygosity and sex.

\begin{tabular}{|c|c|c|c|c|c|c|}
\hline \multirow[b]{2}{*}{ Group } & \multicolumn{3}{|c|}{$\begin{array}{l}\text { Responses for } 5302 \text { pairs where } \\
\text { both twins received the questionnaire and: }\end{array}$} & \multicolumn{2}{|c|}{$\begin{array}{l}\text { Responses for twins from } 51 \\
\text { pairs where only one twin } \\
\text { received the questionnaire }\end{array}$} & \multirow{2}{*}{$\begin{array}{c}\text { Total number of responses } \\
\text { from } 10655 \text { who received } \\
\text { questionnaire } \\
\mathrm{n}(\%)\end{array}$} \\
\hline & $\begin{array}{l}\text { Both twins } \\
\text { responded }(\%)\end{array}$ & $\begin{array}{l}\text { One twin } \\
\text { responded }(\%)\end{array}$ & $\begin{array}{l}\text { Neither twin } \\
\text { responded (\%) }\end{array}$ & $\begin{array}{l}\text { Response } \\
\text { (n) }\end{array}$ & $\begin{array}{l}\text { No response } \\
(\mathrm{n})\end{array}$ & \\
\hline MZM & $403(40.5 \%)$ & $275(27.6 \%)$ & $318(31.9 \%)$ & 2 & 9 & $1083(54.1 \%)$ \\
\hline DZM & $375(28.4 \%)$ & $477(36.1 \%)$ & $470(35.6 \%)$ & 5 & 14 & $1232(46.3 \%)$ \\
\hline MZF & $601(46.1 \%)$ & $227(17.4 \%)$ & $475(36.5 \%)$ & 1 & 9 & $1430(54.7 \%)$ \\
\hline DZF & $549(34.8 \%)$ & $447(28.3 \%)$ & $582(36.9 \%)$ & 2 & 9 & $1547(48.9 \%)$ \\
\hline DZO & $61(59.2 \%)$ & $32(31.1 \%)$ & $10(9.7 \%)$ & 0 & 0 & $154(74.8 \%)$ \\
\hline TOTAL: & $1989(37.5 \%)$ & $1458(27.5 \%)$ & $1855(35.0 \%)$ & $10(19.6 \%)$ & $41(80.4 \%)$ & $5446(51.1 \%)$ \\
\hline
\end{tabular}

questionnaire than DZ twins (probability 0.54 vs. 0.44 , respectively, $\mathrm{p}=0.00)$. However, the response rate did not vary significantly by $\operatorname{sex}(\mathrm{p}=0.10)$, and the probability of responding was 0.52 among females and 0.50 among males. Using the 1935-1944 birth cohort as a reference, response rates among twins in the pairs for which both twins received the questionnaire did not differ among the older cohorts born 1935-1960 (odds ratios are 0.98 (0.86-1.13) for 1945-1954 cohort and $0.91(0.79-1.05)$ for the $1955-1960$ cohort). In contrast, response rates were greater among the youngest group born 1967-1974 (odds ratio is $4.32(3.48-5.36)$ ) in which both twins responded in more than $60 \%$ of the pairs (Figure 2). It is important to note that the NTR was in the process of renewing consent for all twins born 1967-1979 (which includes our youngest group) and thus we were only able to invite those twins in this group who had responded promptly that they would like to continue their participation in the NTR.

Data from four individuals among the 5446 who completed the questionnaire are not included in the final data file as they were received too late. The analyses are thus based on data from 5442 twins (1986 complete pairs and 1470 single responders). The average age of the sample is 61.54 years $(\mathrm{SD}=9.38)$, and the average ages for the groups defined by zygosity and sex are 62.74 ( $\mathrm{SD}=9.26)$ for $\mathrm{MZ}$ males, $63.26(\mathrm{SD}=7.92)$ for $\mathrm{DZ}$ males, $60.35(\mathrm{SD}=10.03)$ for $\mathrm{MZ}$ females, $62.13(\mathrm{SD}=8.47)$ for $\mathrm{DZ}$ females and 44.26 ( $\mathrm{SD}=2.26)$ for $\mathrm{DZ}$ opposite-sexed pairs. The DZO twins are markedly younger because DZO pairs were not recruited into the older cohorts of the NTR. Other descriptive characteristics of the data sample can be found in Table 3 .

\section{Descriptive results for the scales}

Descriptive results for the main social-environmental and psychosocial scales are presented in Table 4, which shows the number of respondents, the number and percent missing on each scale and the means, standard errors, and median values for the untransformed scales. Prior to applying the established algorithms for assigning individual scale scores, we inspected the number of missing items for each scale. For a total scale score to be calculated, more than $75 \%$ of the scale items had to be answered by the respondent, otherwise a missing score was assigned to the scale. If less than $25 \%$ of the items for any scale were missing, then the missing values were replaced by the mean of the non-missing items for that individual. The psycho- 
Table 3. Characteristics of the study sample.

\begin{tabular}{lccc}
\hline Sub-sample (\%) & $\begin{array}{c}\text { Pair responders } \\
(\mathrm{n}=3972)\end{array}$ & $\begin{array}{c}\text { Single responders } \\
(\mathrm{n}=1470)\end{array}$ & $\begin{array}{c}\text { Total } \\
(\mathrm{n}=5442)\end{array}$ \\
\hline Male, \% & 40.7 & 52.5 & 43.9 \\
MZ, \% & 50.5 & 34.4 & 46.1 \\
MZM, \% & 20.2 & 18.9 & 19.9 \\
DZM, \% & 18.9 & 32.8 & 22.6 \\
MZF, \% & 30.2 & 15.5 & 26.2 \\
DZF, \% & 27.6 & 30.6 & 28.4 \\
DZO, \% & 3.1 & 2.2 & 2.8 \\
Education: & & & \\
$\quad$ Grade school or less, \% & 14.6 & 18.2 & 15.6 \\
High school, \% & 41.0 & 43.2 & 41.6 \\
$\quad$ University or higher education $(\leq 4$ years), \% & 23.1 & 22.0 & 22.8 \\
$\quad$ Graduate or professional $(>4$ years), \% & 19.5 & 15.3 & 18.3 \\
Married, \% & 75.9 & 75.8 & 75.9 \\
\hline
\end{tabular}

Table 4. Descriptive results for psychological and social scales among the 5442 respondents.

\begin{tabular}{|c|c|c|c|c|}
\hline Scale & $\mathrm{n}$ missing $(\%)$ & Mean & SD & Median \\
\hline PSS & $108(2.0)$ & 12.47 & 5.30 & 12.00 \\
\hline MHC-SF & $194(3.6)$ & 48.78 & 12.17 & 51.00 \\
\hline CES-D & $105(1.9)$ & 9.94 & 7.66 & 8.00 \\
\hline UCLA loneliness scale & $132(2.4)$ & 31.61 & 8.42 & 30.00 \\
\hline SNI number of roles & $10(0.2)$ & 5.30 & 1.87 & 5.00 \\
\hline SNI number of people & $10(0.2)$ & 25.78 & 22.29 & 20.00 \\
\hline SNI number of embedded networks & $10(0.2)$ & 1.97 & 1.26 & 2.00 \\
\hline Family support & $89(1.6)$ & 3.52 & 0.52 & 3.75 \\
\hline Family support sum* & $89(1.6)$ & 14.07 & 2.10 & 15.00 \\
\hline Family strain & $108(2.0)$ & 1.72 & 0.55 & 1.75 \\
\hline Family strain sum* & $108(2.0)$ & 6.88 & 2.22 & 7.00 \\
\hline Family affectual solidarity & $87(1.6)$ & 3.40 & 0.44 & 3.50 \\
\hline Friends support & $150(2.8)$ & 3.41 & 0.53 & 3.50 \\
\hline Friends support sum* & $150(2.8)$ & 13.62 & 2.13 & 14.00 \\
\hline Friends strain & $153(2.8)$ & 1.56 & 0.48 & 1.50 \\
\hline Friends strain sum* & $153(2.8)$ & 6.24 & 1.93 & 6.00 \\
\hline Friends affectual solidarity & $138(2.5)$ & 3.42 & 0.40 & 3.50 \\
\hline Spouse support & $1113(20.5)$ & 3.71 & 0.47 & 4.00 \\
\hline Spouse support sum* & $1113(20.5)$ & 14.83 & 1.88 & 16.00 \\
\hline Spouse strain & $1119(20.6)$ & 2.04 & 0.60 & 2.00 \\
\hline Spouse strain sum* & $1119(20.6)$ & 8.16 & 2.38 & 8.00 \\
\hline Spouse affectual solidarity & $1104(20.3)$ & 3.33 & 0.46 & 3.38 \\
\hline
\end{tabular}

*Sum refers to the version of the scale score that was calculated by summing items rather than taking the mean.

social and social environmental scales have a rather low number of missing scores (0.18-3.56\%). However, the pattern is different for the scales measuring spouse support and strain where more than $20 \%$ of the participants have missing values. This is explained primarily by these respondents not having a spouse or partner due to being widowed, divorced, separated or never married.

The scale distributions were inspected to guide transformations in preparation for the parametric analyses. We inspected histograms and Q-Q plots of the original data plus histograms and Q-Q plots of the residuals of a linear model accounting for effects of age and sex. We also examined the Box-Cox plots generated from this model. Based on these results, either a continuous or a dichotomous scale transformation was applied as indicated in Table 5.

Continuous transformations (raising to a power or taking the natural logarithm) were applied on the basis of information generated from the Box-Cox plots. The equations used for these transformations are described in Table 5. For the dichotomous transformations, minimum (min), maximum (max) or median (med) of the original scale scores in the whole sample were used as thresholds for dichotomizing. If the minimum was chosen as a threshold, then all the original scale scores that were equal to the minimum were coded as 0 's and all other values were coded as 1's in the dichotomized 
Table 5. Effects of sex, age and number of twins within the pair that responded (pair_response) for the transformed scales.

\begin{tabular}{|c|c|c|c|}
\hline \multirow[b]{2}{*}{ Scale } & \multicolumn{3}{|c|}{ Effects associated with: } \\
\hline & $\mathrm{Sex}^{+}$ & Age $^{++}$ & Pair_response \\
\hline $\mathrm{PSS}^{\#, \mathrm{a}=1}$ & $1.22 *$ & 0.02 & -0.12 \\
\hline MHC-SF ${ }^{\mathrm{a}=2}$ & -6.38 & 3.90 & -57.33 \\
\hline CES-D ${ }^{\#, a=0}$ & $0.23 *$ & $0.01^{*}$ & -0.07 \\
\hline UCLA loneliness scale $\mathrm{e}^{\#, \mathrm{a}=-1}$ & -0.00 & 0.00 & $0.00 *$ \\
\hline SNI number of roles ${ }^{\mathrm{a}=1}$ & $-0.17 *$ & $-0.08 *$ & 0.14 \\
\hline SNI number of people ${ }^{a=0}$ & $-0.13 *$ & $-0.03 *$ & 0.08 \\
\hline Spouse strain $\#, a=0.5$ & -0.01 & 0.00 & 0.01 \\
\hline Spouse strain sum ${ }^{\#, a=0.5}$ & -0.02 & -0.00 & 0.01 \\
\hline SNI number of embedded networks ${ }^{\text {med }}=2$ & $-0.22 *$ & $-0.05 *$ & 0.06 \\
\hline Family support $^{\max =4}$ & $0.23 *$ & 0.01 & 0.05 \\
\hline Family support sum ${ }^{\max =16}$ & $0.23 *$ & 0.01 & 0.05 \\
\hline Family strain $^{\min =1}$ & 0.17 & $-0.02 *$ & -0.06 \\
\hline Family strain sum ${ }^{\min =4}$ & 0.17 & $-0.02 *$ & -0.06 \\
\hline Family affectual solidarity ${ }^{\text {med }=3.5}$ & -0.03 & $0.01 *$ & 0.08 \\
\hline Friends support $^{\mathrm{med}=3.5}$ & $0.88 *$ & $-0.02 *$ & -0.02 \\
\hline Friends support sum ${ }^{\text {med=14 }}$ & $0.88 *$ & $-0.02 *$ & -0.02 \\
\hline Friends strain ${ }^{\#, \min =1}$ & -0.08 & -0.01 & -0.03 \\
\hline Friends strain sum ${ }^{\#, \min =4}$ & -0.08 & -0.01 & -0.03 \\
\hline Friends affectual solidarity ${ }^{\text {med }=3.5}$ & $0.53^{*}$ & -0.00 & -0.05 \\
\hline Spouse support ${ }^{\max =4}$ & $-0.45^{*}$ & 0.00 & -0.03 \\
\hline Spouse support sum ${ }^{\max =16}$ & $-0.45 *$ & 0.00 & -0.03 \\
\hline \multicolumn{4}{|l|}{ Sex is coded as $0=$ male, $1=$ female. } \\
\hline \multicolumn{4}{|c|}{ Age was centered on the mean age of the sample ( 62 years). } \\
\hline \multicolumn{4}{|c|}{ Scale is scored in such a way that a higher value means less positive psychological or social well-being. } \\
\hline \multicolumn{4}{|c|}{$\begin{array}{l}\text { Continuous scale transformations: } \mathrm{z}=\mathrm{y}^{\mathrm{a}} \text { (if } a \neq 0 \text { ) or } \mathrm{z}=\log (\mathrm{y}+1 / 10 * m) \text { (for } a=0 \text { and } \mathrm{m} \text { the minimal positive } \mathrm{y} \text { ) where } \mathrm{y} \text { and } \mathrm{z} \text { are original and } \\
\text { transformed scale scores, respectively. If } a=0 \text {, the natural logarithm of the original scores was taken (to ensure non-zero values, a tenth of } \\
\text { the minimum positive value was added to each original score before taking the logarithm); for } a \neq 0 \text { raising to the power } a \text { was applied. }\end{array}$} \\
\hline \multicolumn{4}{|c|}{$\begin{array}{l}\text { Distributions of the scales listed below the dotted line were dichotomized using transformations whereby the minimum (min), maximum } \\
\text { (max) or median (med) of the original scale scores were used as thresholds for dichotomizing. }\end{array}$} \\
\hline $\mathrm{p} \leq 0.01$ & & & \\
\hline
\end{tabular}

variable. If the median was chosen as a threshold, then all the original scale scores that were lower than or equal to the median were coded as 0 's and all other values were coded as 1's in the dichotomized variable. If the maximum was chosen as a threshold, then all the original scale scores that were lower than the maximum were coded as 0 's and all other (i.e. all equal to the maximum) were coded as 1 's in the dichotomized variable.

Simple descriptive analyses of the scales or their relevant transformed versions were then conducted. We fit a simple generalized estimating equation (GEE) model $Y=s e x+$ age + pair response, where $\mathrm{Y}$ is a chosen scale, age is centered around the mean of age 62 from the total sample and pair response is an indicator for whether responses were received from only one or from both twins within a pair. Results are reported in Table 5 .

To provide a general overview of incidence in our data, Table 6 shows the number of pairs concordant and discordant for CVD and cancer, stratified by zygosity, and with separate columns reflecting the source of the CVD diagnosis. In the subsample where both twin responded, 1651 individuals $(42 \%)$ had at least one
CVD-related problem or diagnosis as measured by the combined information from the NCDR and the questionnaire. Among these, 753 reported high blood pressure only. For cancer, 324 individuals (8\%) had received a diagnosis in the NCR.

\section{DISCUSSION}

We describe a new twin study that will explore social environments and their effects on diverse health and functional outcomes in twins aged 40-80 years, with an average age of 61.54 years. Among the 10655 twins who received the questionnaire (5302 pairs plus 51 single twins), responses were received from 5446 individuals (1989 pairs and 1468 single responders). The overall individual and pairwise response rates were $51 \%$ and $38 \%$, respectively. These response rates are lower than in our earlier questionnaire studies (73\% individual and 63\% pairwise (46), and 63\% individual and 53\% pairwise (47)). Reduced response rates are consistent with a general downward trend in participation that has been observed in epidemiological studies (48). While we are unable to determine the degree to which our response rates reflect this general 
Table 6. Concordance for CVD and cancer diagnoses based on sample of responding pairs.

\begin{tabular}{|c|c|c|c|c|c|c|c|c|c|c|c|c|}
\hline & \multicolumn{3}{|r|}{$\mathrm{NCDR}^{\mathrm{a}}$} & \multicolumn{3}{|c|}{ Questionnaire CVD ${ }^{\mathrm{b}}$} & \multicolumn{3}{|c|}{$\begin{array}{c}\text { Any CVD, } \text { NCDR }^{\mathrm{a}} \text { or } \\
\text { Questionnaire }^{\mathrm{b}}\end{array}$} & \multicolumn{3}{|c|}{$\begin{array}{c}\text { Cases Cancer Registry, } \\
\text { diagnosis } \geq 1^{\mathrm{c}}\end{array}$} \\
\hline & $\begin{array}{l}+/+ \\
(\mathrm{N}) \\
\end{array}$ & $\begin{array}{l}+/- \\
(\mathrm{N})\end{array}$ & $\begin{array}{c}\text { Casewise } \\
\text { Condordance } \\
(95 \% \mathrm{CI})\end{array}$ & $\begin{array}{l}+/+ \\
(\mathrm{N}) \\
\end{array}$ & $\begin{array}{l}+/- \\
(\mathrm{N}) \\
\end{array}$ & $\begin{array}{c}\text { Casewise } \\
\text { Condordance } \\
(95 \% \mathrm{CI})\end{array}$ & $\begin{array}{l}+/+ \\
(\mathrm{N}) \\
\end{array}$ & $\begin{array}{l}+/- \\
(\mathrm{N})\end{array}$ & $\begin{array}{c}\text { Casewise } \\
\text { Condordance } \\
(95 \% \mathrm{CI})\end{array}$ & $\begin{array}{l}+/+ \\
(\mathrm{N})\end{array}$ & $\begin{array}{l}+/- \\
(\mathrm{N})\end{array}$ & $\begin{array}{c}\text { Casewise } \\
\text { Condordance } \\
(95 \% \mathrm{CI})\end{array}$ \\
\hline MZM & 28 & 97 & $0.37(0.27-0.46)$ & 115 & 123 & $0.65(0.59-0.71)$ & 132 & 127 & $0.68(0.62-0.73)$ & 14 & 40 & $0.41(0.26-0.56)$ \\
\hline DZM & 20 & 104 & $0.28(0.18-0.37)$ & 77 & 156 & $0.50(0.43-0.57)$ & 89 & 166 & $0.52(0.45-0.58)$ & 5 & 57 & $0.15(0.03-0.27)$ \\
\hline $\mathrm{MZF}$ & 19 & 117 & $0.25(0.16-0.33)$ & 140 & 149 & $0.65(0.60-0.70)$ & 154 & 174 & $0.64(0.59-0.69)$ & 10 & 85 & $0.19(0.09-0.29)$ \\
\hline $\mathrm{DZF}$ & 11 & 104 & $0.17(0.09-0.26)$ & 81 & 200 & $0.45(0.38-0.51)$ & 95 & 222 & $0.46(0.40-0.52)$ & 1 & 79 & $0.02(-0.02-0.07)$ \\
\hline DZO & 1 & 7 & $0.23(-0.14-0.58)$ & 2 & 15 & $0.21(-0.03-0.46)$ & 4 & 14 & $0.36(0.11-0.62)$ & 0 & 3 & - \\
\hline
\end{tabular}

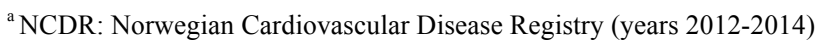

${ }^{\mathrm{b}}$ Self-reported CVD disease

${ }^{\mathrm{c}}$ Cases counted based on year of first diagnosis (case in Cancer Registry 1952). All cases have one or more diagnoses.

${ }^{+/+}$Pairs concordant for disease

+/- Pairs discordant for disease

trend, other factors may also be at play. For example, our sample was much older and our questionnaire substantially longer than in our previous studies. We were unable to conduct a full assessment of the reasons for non-participation, 47 individuals voluntarily provided feedback about why they opted not to participate. Health and function-related problems were clearly the most common explanation $(n=31)$. Death or illness in the family was the second most common reason. Our information is quite limited as it is based on only 47 individuals from among several thousand non-responders, it does however reflect many of the commonly known reasons for non-response. Health problems are a well-known source of non-participation in epidemiological studies, particularly among older samples where a greater frequency of cognitive impairment and other health issues interfere with completing the questionnaire. Indeed, response rates were greater among the youngest group in our sample. Our study also contained some particularly personal items inquiring about closeness, conflict and support with family members, including the spouse and co-twin. Some individuals provided feedback that they found these questions too intrusive, but then the tendency was to abstain from answering those questions rather than not participate in the study. The largest source of bias due to nonresponse is most likely reduced variation in the health outcomes. However, our preliminary analyses reveal that the variation in the data from the responding sample is sufficient to explore the relationships between the psychosocial measures and their impact on health in this functional sample.

As is typical for twin studies, MZ twins were more likely to participate than DZ twins. In addition, we did not observe the well-known sex differences in response rates overall; men were as likely to participate as women. However, when we limit to pairs where both twins responded, we see that males comprise a smaller percentage $(40.7 \%)$ of the sample. This reflects, in part, sex differences in the composition of the original sample (43\% men and $57 \%$ women).
We conducted preliminary analyses of the measures to characterize the trends in our data. Sex effects were significant $(p \leq 0.01)$ for many scales but not for MHC-SF, loneliness, family affectual solidarity and strain scales (spouse, family and friends). Compared to men, women reported higher levels of perceived stress and depressive symptomatology, higher levels of support from family and friends, but lower levels of spouse support. Men scored higher on indices of social networking as reflected by the number of social roles and number of embedded networks. Age effects were significant $(\mathrm{p} \leq 0.01)$ for CES-D and SNI scales, for family strain and family affectual solidarity, and for friends support. In general, age was positively associated with higher levels of depressive symptomatology, and less contacts and networks as measured by SNI, but with better levels of family affectual solidarity. Friends support, however, decreased with age, as did reported strain from family.

We also tested whether the number of twins within the pair who responded to the questionnaire was predictive of scores on the psychosocial and social environmental measures. Tests of differences between the individuals from pairs where both twins responded versus just one twin responded could provide insights into potential bias in our data if the values from doubly-responding pairs reveal that the scores for these individuals differed significantly and consistently in ways that reflected greater closeness and co-twin solidarity. We found a positive association $(\mathrm{p} \leq 0.01)$ only for the UCLA loneliness scale, however, the estimate of the effect was very close to zero. Scores for the other psychosocial and social environmental scales did not differ between the individuals from pairs where both twins responded versus pairs where only one twin responded.

Estimates of concordance and discordance for CVD-related outcomes and for cancer reveal greater MZ than DZ similarity. These values were generated in preliminary analyses to provide frequency overviews for the sample of participating pairs, and should be 
interpreted with caution for several reasons. The NCDR registry was established in 2012 and therefore cases occurring prior to that are missed. We have supplemented with information from our questionnaire to form a highly varied category of CVD-related outcomes. Likewise, our cancer data obtained through linkage to the national cancer registry was complete through November 2102, so it will not include cases occurring after that date. These gaps can be filled through updated matches of our data to the NCDR and CVD registries. Importantly, the current values reveal sufficient variation in these health measures, showing concordance and discordance across zygosity groups, to analyze models of the relationships with the psychosocial and social environmental measures.

\section{SUMMARY}

We describe a new twin study designed to investigate social worlds and their relationship to health and wellbeing in a Norwegian population. The data collected from these twins aged 40-80 years, including record linkage to the CVD and Cancer registries, will provide a strong basis for understanding the importance of genetic and environmental influences on social worlds.
This will enable us to research how diverse types of social environments modify heritable effects on different health outcomes, and permit an investigation of the relationship between social factors and health while controlling for genetic and background environmental effects. Despite lower response rates than in our previous studies, our preliminary examination of the scales show low rates of missing items and a good range of variation reflected in the scale scores capturing the full range of variation. The presence of a large sample of twins whose co-twin did not respond allows us to also test for differences in the pair versus single responders, and to exploit models that use the single responders as random pairs in statistical applications to test for causal versus pleiotropic effects (49). We hope to continue to build this program of research through collaboration with other twin studies and through the addition of biological and genetic data that would allow more detailed investigations of how social environments 'get under the skin' to affect health and well-being.

\section{ACKNOWLEDGEMENT}

We thank the twins for their participation.

\section{REFERENCES}

1. Cacioppo JT, Hughes ME, Waite LJ, Hawkley LC, Thisted RA. Loneliness as a specific risk factor for depressive symptoms: cross-sectional and longitudinal analyses. Psychol Aging 2006;21:140-151.

2. Hawkley LC, Masi CM, Berry JD, Cacioppo JT. Loneliness is a unique predictor of age-related differences in systolic blood pressure. Psychol Aging 2006;21:152-164.

3. House JS, Landis KR, Umberson D. Social relationships and health. Science 1988;241:540-545.

4. Marmot M. Health in an unequal world: social circumstances, biology and disease. Clin Med 2006;6:559-572.

5. Ryff CD, Singer BH. Social environments and the genetics of aging: advancing knowledge of protective health mechanisms. J Gerontol B Psychol Sci Soc Sci 2005;60 Spec No 1:12-23.

6. Wen M, Hawkley LC, Cacioppo JT. Objective and perceived neighborhood environment, individual SES and psychosocial factors, and self-rated health: an analysis of older adults in Cook County, Illinois. Soc Sci Med 2006;63:2575-2590.

7. Singer B, Ryff CD. Hierarchies of life histories and associated health risks. Ann N Y Acad Sci 1999;896:96115.

8. Seeman TE. Social ties and health: the benefits of social integration. Ann Epidemiol 1996;6:442-451.

9. Seeman TES, B.; Ryff, C.; Levy-Storms, L. Psychosocial factors and the development of allostatic load. Psychosom Med 2002:395-406.

10. Bassuk SS, Glass TA, Berkman LF. Social disengagement and incident cognitive decline in communitydwelling elderly persons. Ann Intern Med 1999;131:165-173.

11. Eisenberger NI, Cole SW. Social neuroscience and health: neurophysiological mechanisms linking social ties with physical health. Nat Neurosci 2012;15:669-674.

12. Fratiglioni L, Wang HX, Ericsson K, Maytan M, Winblad B. Influence of social network on occurrence of dementia: a community-based longitudinal study. Lancet 2000;355:1315-1319.

13. Seeman TE, Lusignolo TM, Albert M, Berkman L. Social relationships, social support, and patterns of cognitive aging in healthy, high-functioning older adults: MacArthur studies of successful aging. Health Psychol 2001;20:243-255.

14. Miller GE, Chen E, Fok AK, Walker H, Lim A, Nicholls EF, Cole S, Kobor MS. Low early-life social class leaves a biological residue manifested by decreased glucocorticoid and increased proinflammatory signaling. Proc Natl Acad Sci USA 2009;106:14716-14721.

15. Seeman TE, McEwen BS. Impact of social environment characteristics on neuroendocrine regulation. Psychosom Med 1996;58:459-471.

16. Pavela G. Functional status and social contact among older adults. Res Aging 2015;37:815-836. 
17. Holt-Lunstad J, Smith TB, Layton JB. Social relationships and mortality risk: a meta-analytic review. PLoS Med 2010;7:e1000316.

18. Seeman TE, Crimmins E. Social environment effects on health and aging: integrating epidemiologic and demographic approaches and perspectives. Ann N Y Acad Sci 2001;954:88-117.

19. Jaremka LM, Glaser R, Malarkey WB, Kiecolt-Glaser JK. Marital distress prospectively predicts poorer cellular immune function. Psychoneuroendocrinology 2013;38:2713-2719.

20. Seeman TE, Gruenewald TL, Cohen S, Williams DR, Matthews KA. Social relationships and their biological correlates: Coronary Artery Risk Development in Young Adults (CARDIA) study. Psychoneuroendocrinology 2014;43:126-138.

21. Seeman TE, Singer BH, Ryff CD, Dienberg Love G, Levy-Storms L. Social relationships, gender, and allostatic load across two age cohorts. Psychosom Med 2002;64:395-406.

22. Brooks KP, Gruenewald T, Karlamangla A, Hu P, Koretz B, Seeman TE. Social relationships and allostatic load in the MIDUS study. Health Psychol 2014;33:1373-1381.

23. Yang YC, McClintock MK, Kozloski M, Li T. Social isolation and adult mortality: the role of chronic inflammation and sex differences. J Health Soc Behav 2013;54:183-203.

24. Steptoe A, Shankar A, Demakakos P, Wardle J. Social isolation, loneliness, and all-cause mortality in older men and women. Proc Natl Acad Sci USA 2013;110:5797-5801.

25. Epel ES, Blackburn EH, Lin J, Dhabhar FS, Adler NE, Morrow JD, Cawthon RM. Accelerated telomere shortening in response to life stress. Proc Natl Acad Sci USA 2004;101:17312-17315.

26. Kiecolt-Glaser JK, Glaser R, Cacioppo JT, MacCallum RC, Snydersmith M, Kim C, Malarkey WB. Marital conflict in older adults: endocrinological and immunological correlates. Psychosom Med 1997;59:339-349.

27. Cohen S. Keynote Presentation at the Eight International Congress of Behavioral Medicine: the Pittsburgh common cold studies: psychosocial predictors of susceptibility to respiratory infectious illness. Int J Behav Med 2005;12:123-131.

28. Cohen S, Janicki-Deverts D, Miller GE. Psychological stress and disease. JAMA 2007;298:1685-1687.

29. Ramey SL, Perkhounkova Y, Downing NR, Culp KR. Relationship of cardiovascular disease to stress and vital exhaustion in an urban, midwestern police department. AAOHN J 2011;59:221-227.

30. Penwell LM, Larkin KT. Social support and risk for cardiovascular disease and cancer: a qualitative review examining the role of inflammatory processes. Health Psychol Rev 2010;4:42-55.

31. Cacioppo JT, Hawkley LC. Social isolation and health, with an emphasis on underlying mechanisms. Perspect Biol Med 2003;46:S39-S52.

32. Yang YC, Boen C, Gerken K, Li T, Schorpp K, Harris KM. Social relationships and physiological determinants of longevity across the human life span. Proc Natl Acad Sci USA 2016;113:578-583.

33. Isaeva JS, Hamdi NR, Krueger RF, Harris JR. The variance and covariance structure of social environments. Poster for the 15th International Congress on Twin Studies and the 3rd World Congress on Twin Pregnancy, Budapest, Hungary, 2014.

34. Nilsen TS, Brandt I, Magnus P, Harris JR. The Norwegian Twin Registry. Twin Res Hum Genet 2012;15: $775-780$.

35. Nilsen TS, Knudsen GP, Gervin K, Brandt I, Roysamb E, Tambs K, Orstavik R, Lyle R, ReichbornKjennerud T, Magnus P, Harris JR. The Norwegian Twin Registry from a public health perspective: a research update. Twin Res Hum Genet 2013;16:285-295.

36. Cohen S, Kamarck T, Mermelstein R. A global measure of perceived stress. J Health Soc Behav 1983;24:385396.

37. Cohen S, Doyle WJ, Skoner DP, Rabin BS, Gwaltney JM, Jr. Social ties and susceptibility to the common cold. JAMA 1997;277:1940-1944.

38. Russell DW. UCLA Loneliness Scale (Version 3): reliability, validity, and factor structure. J Pers Assess 1996;66:20-40.

39. Schuster TL, Kessler RC, Aseltine RH, Jr. Supportive interactions, negative interactions, and depressed mood. Am J Community Psychol 1990;18:423-438.

40. Whalen HR, Lachman ME. Social support and strain from partner, family and friends: Cost and benefits for men and women in adulthood. J Soc Pers Relationships 2000;17:5-30.

41. Radler BT. The Midlife in the United States (MIDUS) Series: A National Longitudinal Study of Health and Well-being. Open Health Data 2014;2.

42. Radloff LS. The CES-D Scale: A Self-Report Depression Scale for Research in the General Population. Applied Psychological Measurement 1977;1:385-401.

43. Keyes CLM. Atlanta: Brief description of the mental health continuum short form (MHC-SF). Available: http://wwwsociologyemoryedu/ckeyes/, 2009. 
44. Egeland GM, Sundvor V, Igland J, Seliussn I, Klakegg Y, Vollset SE, Akerkar R, Tell GS, Ebbing M. Opportunities for diabetes research using the Norwegian Cardiovascular Disease Registry. Norsk Epidemiologi 2013;23:95-100.

45. Witte JS, Carlin JB, Hopper JL. Likelihood-based approach to estimating twin concordance for dichotomous traits. Genet Epidemiol 1999;16:290-304.

46. Harris JR, Tambs K, Magnus P. Sex-specific effects for body mass index in the new Norwegian twin panel. Genet Epidemiol 1995;12:251-265.

47. Harris JR, Magnus P, Tambs K. The Norwegian Institute of Public Health twin program of research: an update. Twin Res Hum Genet 2006;9:858-864.

48. Galea S, Tracy M. Participation rates in epidemiologic studies. Ann Epidemiol 2007;17:643-653.

49. Ligthart L, Boomsma DI. Causes of comorbidity: pleiotropy or causality? Shared genetic and environmental influences on migraine and neuroticism. Twin Res Hum Genet 2012;15:158-165. 